\title{
中耳腔陽圧を示す tympanogram における音響性耳小骨筋反射
}

はじめに

乳幼児の聴力検查として, 一般に聴性行動反応検査 (BOA), 条件詮索反応検査 (COR), 睡眠時の聴性脳 幹反応検査 $(\mathrm{ABR})$ が行われる。インピーダンスオー ジオメトリーも乳幼児における検査項目として欠かせ ないものであり, tympanometry は客観的に鼓膜の可 動性や中耳の病態を表わし，また，音響性耳小骨筋反 射 (acoustic reflex. AR) の測定は客観的に聴力障害 の程度を観察するに参考となる。

われわれは，睡眠時 ABR 検査後，睡眠が続いてい る場合に tympanometry, AR を測定しているが, そ の際に中耳腔が陽圧であることを示す，すなわちピー クの位置がプラス (十)を示す tympanogram (+A 型) が高率にみられることを報告した1)。

今回は, AR 検出耳が tympanogram $+\mathrm{A}$ 型の AR 域值を $\mathrm{A}$ 型と比較し, + A 型であることが $\mathrm{AR}$ 測定結 果に影響を及ぼすかを検討した。また, + A 型の検出 耳において, 測定時の外耳道圧の変化による AR 域值 への影響を検討した。

\section{対象}

昭和 55 年 8 月から昭和 60 年 12 月までに茨城県メディ カルセンター内聴覚センターにおいて, 睡眠時の $\mathrm{ABR}$ 検查後, 引き続いて tympanometry 及び $\mathrm{AR}$ 測 定を実施し得た乳幼児は118名220耳であった。このう ち, tympanogram が+A 型を示し, 対側耳（AR 測 定の音刺激耳) の聴力が正常と推定された 34 名 53 耳と, tympanogram がA型を示し, 同じく対側耳の聴力が 正常と推定された 16 名 20 耳を対象とした。

聴力正常の推定根拠は, COR, BOA で明確に反応
茨城県メディカルセンター内聴覚センター

岡田慎一

筑波大学臨床医学系耳鼻咽喉科

阿瀬雄治

国立霞ケ浦病院耳鼻咽喉科

新井 峻

が認められ， $\mathrm{ABR}$ 域值が $30 \mathrm{~dB}$ (nHL) 以下で反応波 形の乱れ，潜時の遅れが無い耳とした。

対象児の年令分布は表 1 に示す。

表 1 対象览の年令分布

\begin{tabular}{r|cccccccc}
\hline 年 $\quad$ 令 & 0 & 1 & 2 & 3 & 4 & 5 & 6 & 計 \\
\hline + $\mathrm{A}$ 型 & 2 & 8 & 14 & 6 & 2 & 1 & 1 & 34 \\
$\mathrm{~A}$ 型 & 2 & 2 & 7 & 3 & 1 & 1 & & 16 \\
\hline
\end{tabular}

方法

インピーダンスオージオメータは，テレダイン製 TA-2C を使用した。tympanometry 測定時における 外耳道内への加圧, 減圧は $+200 \mathrm{mmH}_{2} \mathrm{O}$ より減圧す る方向に掃引記録した。AR は contralateral で測定 し, 純音刺激 $(1000 \mathrm{~Hz}$ ，余裕があれば $500,2000,4000$ $\mathrm{Hz}$ )を用いた。 $\mathrm{AR}$ 測定時の外耳道圧は原則として tympanogram のピークに一致させた。

被検児に対する睡眠誘導体としてトリクロリールシ ロップ体重 $1 \mathrm{~kg}$ 当り $1 \mathrm{cc}(100 \mathrm{mg})$ を服用させた。

以上の条件下で, 検出耳の tympanogram が+A 型，A型それぞれの AR 域值を求めた。

また, $+\mathrm{A}$ 型のうち13例については, 測定時の外耳 道圧を tympanogram のピークに一致させないで，0 $\mathrm{mmH}_{2} \mathrm{O}$ にて AR を測定しピークに一致させた場合 と比較した。刺激音は $1000 \mathrm{~Hz}$ または $500 \mathrm{~Hz}$ で実施し た。

\section{結果}

1. Tympanogram $+\mathrm{A}$ 型のピーク分布 


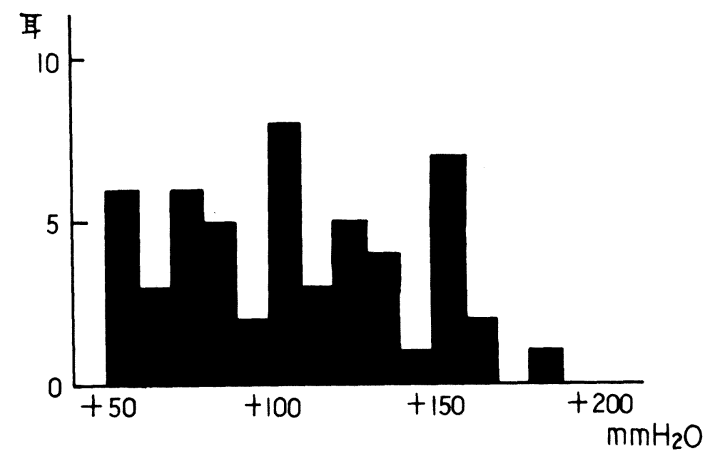

図 1 対象耳 tympanogram+A型のピークにおける 中耳圧分布

$+50 \mathrm{mmH}_{2} \mathrm{O}$ 以上の陽圧にピークのある tympanogram を+ A 型と称している1)。今回対象の+ A 型の ピーク分布は, $+50 \mathrm{mmH}_{2} \mathrm{O}$ から $+180 \mathrm{mmH}_{2} \mathrm{O}$ の範 囲で, 平均 $+102.3 \mathrm{mmH}_{2} \mathrm{O}$ であった（図 1 ）。

2. 音響性耳小骨筋反射域値について

$+\mathrm{A}$ 型, $\mathrm{A}$ 型それぞれの $\mathrm{AR}$ 域值平均值を周波数別 に示した（表 2 )。域値の差は $\mathrm{A}$ 型を基準として, 500 $\mathrm{Hz}$ で-1.9dB, $1000 \mathrm{~Hz}$ で+0.3dB, $2000 \mathrm{~Hz}$ で-1.5 $\mathrm{dB}, 4000 \mathrm{~Hz}$ で+7.3dB であった。 $4000 \mathrm{~Hz}$ で+A型 がやや高い傾向がみえる程度で差は大きくなく, いず れも各周波数 $100 \mathrm{~dB}$ (HL) 前後の $\mathrm{AR}$ 域值であり,+ $\mathrm{A}$ 型， $\mathrm{A}$ 型間に明らかな差は認められなかった。

表 2 の平均值は AR が検出し得た例についてのも ので, AR の得られない例もある。+ $\mathrm{A}$ 型, $\mathrm{A}$ 型それぞ れの $\mathrm{AR}$ 陽性率を示したのが表 3 である。各周波数と も, AR の得られない例があるが $4000 \mathrm{~Hz}$ は最も陽性率 が低く, 特に+ A 型では $44.8 \%$ と半数以上で $\mathrm{AR}$ が得 られなかった。個々の症例では, 全周波数とも $\mathrm{AR} の$ 得られない耳が+ A型で 4 耳, $\mathrm{A}$ 型で 1 耳あった。 型の 4 耳は 2 名の被検児の両耳である。

\section{3. 外耳道圧の影響}

+ A 型の耳において, 外耳道圧を tympanogram の

表 2 音響性耳小骨筋反射域值の平均值

\begin{tabular}{c|cccc}
\hline $\begin{array}{r}\text { 刺激音周波数 } \\
(\mathrm{Hz})\end{array}$ & 500 & 1000 & 2000 & 4000 \\
\hline $\mathrm{A}$ 型 $(\mathrm{dB})$ & $\begin{array}{r}98.6 \\
(18)\end{array}$ & $\begin{array}{c}97.8 \\
(18)\end{array}$ & $\begin{array}{c}101.4 \\
(18)\end{array}$ & $\begin{array}{c}97.7 \\
(11)\end{array}$ \\
\hline$+\mathrm{A}$ 型 $(\mathrm{dB})$ & $\begin{array}{r}96.7 \\
(42)\end{array}$ & $\begin{array}{c}98.1 \\
(49)\end{array}$ & $\begin{array}{c}99.9 \\
(35)\end{array}$ & $\begin{array}{c}105.0 \\
(13)\end{array}$ \\
\hline \multicolumn{4}{c}{$(\quad)$ は, 対象耳数 }
\end{tabular}

表 3 音響性耳小骨反射陽性率

\begin{tabular}{|c|c|c|c|c|c|}
\hline \multicolumn{2}{|c|}{$\begin{array}{c}\text { 刺激音周波数 } \\
(\mathrm{Hz})\end{array}$} & 500 & 1000 & 2000 & 4000 \\
\hline \multirow{3}{*}{ A 型 } & $\mathrm{AR}+$ & 18 & 18 & 18 & 11 (耳) \\
\hline & A R - & 1 & 2 & 1 & 5(耳) \\
\hline & 陽性率 & 94.7 & 90.0 & 94.7 & $68.8(\%)$ \\
\hline \multirow{3}{*}{ + A 型 } & $\mathrm{AR}+$ & 42 & 49 & 35 & 13(耳) \\
\hline & A R - & 4 & 4 & 8 & 16 (耳) \\
\hline & 陽性率 & 91.3 & 92.5 & 81.4 & $44.8(\%)$ \\
\hline
\end{tabular}

ピークに一致させず $0 \mathrm{mmH}_{2} \mathrm{O}$ で測定すると，13例中 7 例 (54\%) で AR が検出し得なくなり, 残る 6 例も ピークに一致させての測定より AR 域値が上昇した (図 2)。域值の上昇は $5 \mathrm{~dB}$ にとどまった例もあるが, $20 \mathrm{~dB} ， 30 \mathrm{~dB}$ と大きな上昇值を示した例があった。

図 3 は, ピークに一致させない測定で $\mathrm{AR}$ 域值が上 昇した例である。ピークに一致させた測定より $5 \mathrm{~dB}$ 上 昇し,さらに音圧を増しても $\mathrm{AR}$ 振幅の増大傾向が少

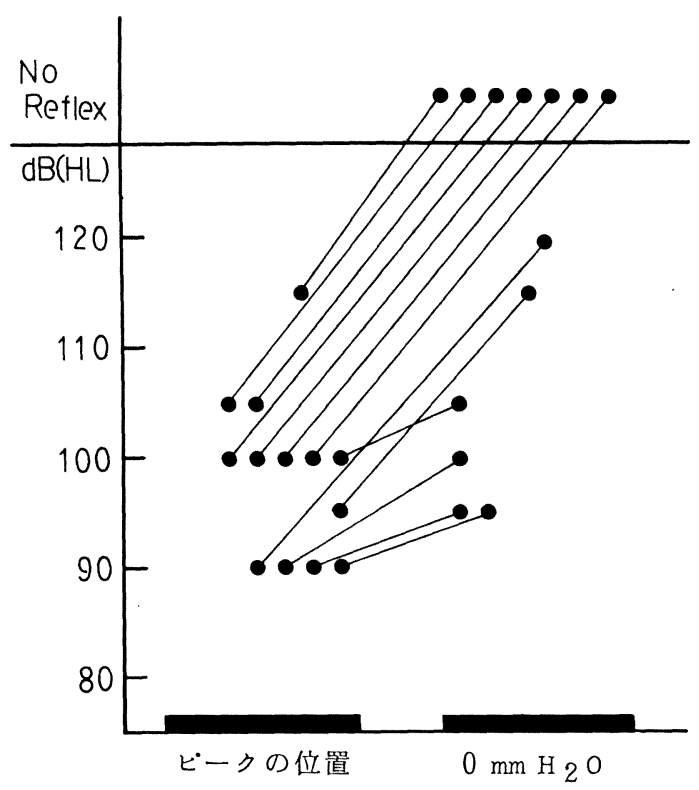

図 2 Tympanogram $+\mathrm{A}$ 型においての外耳道圧と AR 域值

AR 測定時の外耳道圧を tympanogram のピー クに一致させた場合と,ピークに一致させず $0 \mathrm{~mm}$ $\mathrm{H}_{2} \mathrm{O}$ にした場合との AR 域值を比較した。ピー クに一致させないと $\mathrm{AR}$ が検出し得ない例が多く, 13 例中 7 例に及んだ。刺激音は $1000 \mathrm{~Hz}$ または $500 \mathrm{~Hz}$ 。 

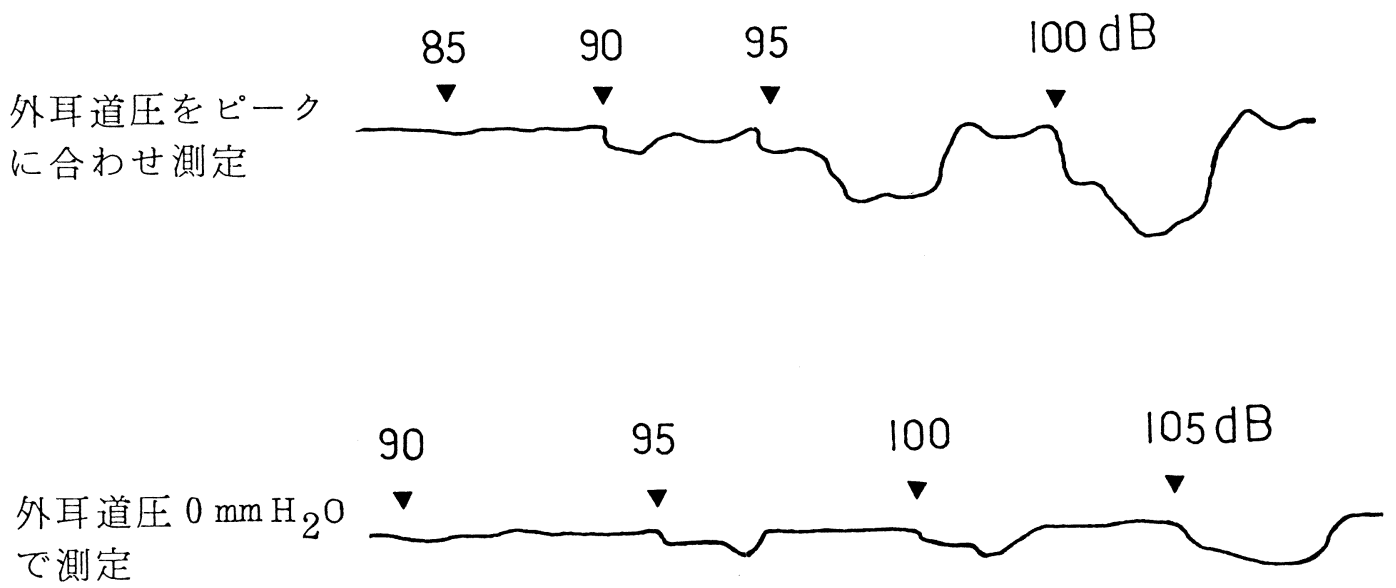

図 $3 \mathrm{AR}$ 測定時の外耳道圧を tympanogram のピークに一致させないと域值が上昇し, かつ刺激を増 強しても振幅の増大傾向が少ない。

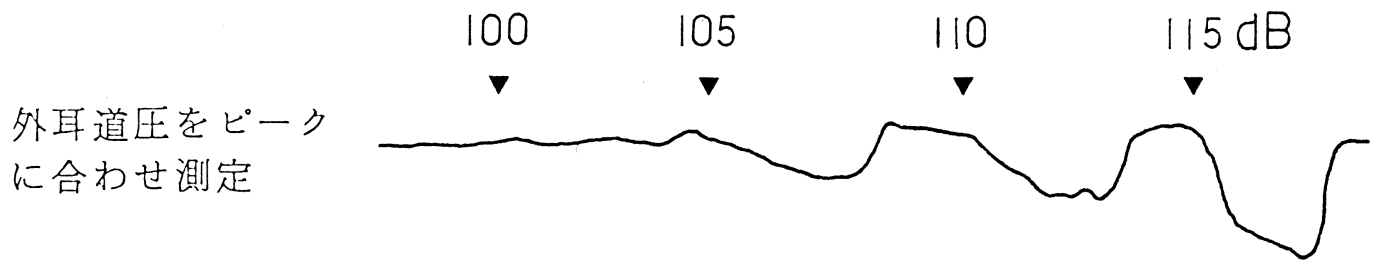

外耳道王 $0 \mathrm{~mm} \mathrm{H}_{2} \mathrm{O}$

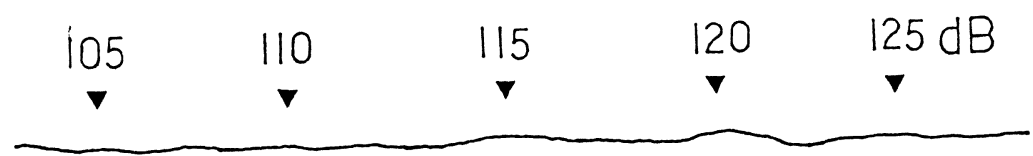

で測定

図 $4 \mathrm{AR}$ 測定時の外耳道圧を tympanogram のピークに一致させないと AR が検出されなくなった。 ない。

図 4 は,ピークに一致させない測定で AR が検出し 得なくなった例である。ピークに一致させた測定では $105 \mathrm{~dB}$ の AR 域值であったが，ピークに一致させない と検査機器の最大出力音圧刺激でも $\mathrm{AR}$ は検出され ない。

\section{考察}

AR を測定するにはいくつかの方法があるが, イン ピーダンスオージオメトリーが一般的である。AR の 出現はアブミ骨筋の収縮により probe tone $220 \mathrm{~Hz}$ に おける鼓膜のコンプライアンスを低下させる。インピ ーダンスオージオメトリーは AR をこの鼓膜のコン プライアンスの変化としてとらえるため, 検出耳の状 態に左右される。すなわち, 検出耳の中耳に病変があ れば AR 測定は不能, または困難となる。従って, AR 測定前に実施する tympanometry の所見が重要で, 中 耳の病変を示す tympanogram B 型, C 型では $\mathrm{AR}$ 検 出はむずかしく, A 型を示すことが AR 測定の条件と なる。

睡眠下の乳幼児において得られる tympanogram+ A 型の成因は不明である。しかし, 高率にみられ, 耳 管の機能は良く ${ }^{1)}$, 中耳の病変によるもので無いのは 明らかであり生理的なものと考えられる。従って, こ の点においてはAR 測定の対象になる。今回, 検出耳 が十 A型, すなわち中耳腔が陽圧であることが AR 測 


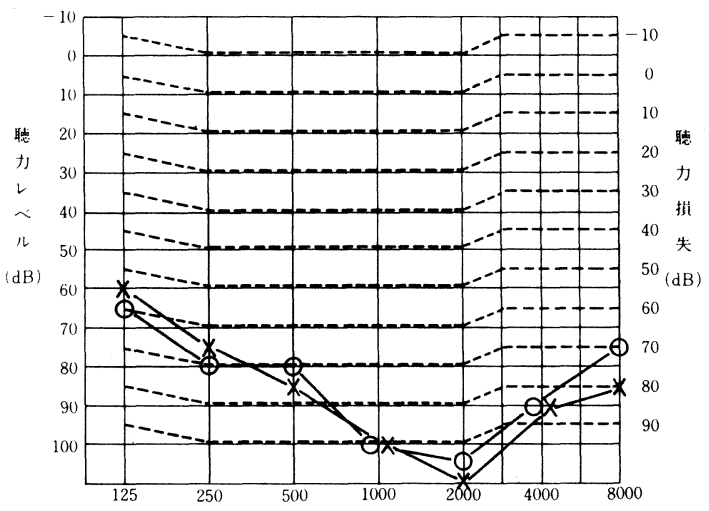

図 $5 \mathrm{ABR}$ が無反応で AR が検出された症例

オージオグラムは 4 歳時に得られたものである。 1 歳時の ABR 検査は反応が認められなかったが, $500 \mathrm{~Hz}$ の刺激でのみ $\mathrm{AR}$ が検出された。

定に影響を及ぼすかどうかを知るため, + A 型と A 型 の AR 域值を比較したが明らかな差はなかった。中耳 腔が陽圧であることは $\mathrm{AR}$ 域値に影響を及ぼさない か，及ぼしてもわずかであると思われる。

$+\mathrm{A}$ 型， A 型とも AR の得られない例があり，特 に+ A 型の $4000 \mathrm{~Hz}$ が最も陽性率が低かった。猪ら ${ }^{2)}$ は 聴力正常児の $4000 \mathrm{~Hz}$ の AR 陽性率は55.9\%（原文は 欠除率 $44.1 \%$ ）であったと報告している。報告内容か ら A 型の耳検出の結果と思われるが，この陽性率は今 回の A 型よりも低く,どちらかというと+A型に近い。 Jerger ら ${ }^{3)}$ は 6 歳未満の被検児で最もAR が欠除し たのは $4000 \mathrm{~Hz}$ であったと報告している。成人におい ても AR 欠除は $4000 \mathrm{~Hz}$ に多い4)。 $4000 \mathrm{~Hz}$ は AR が得 にくいことを念頭に置いて結果を判定する必要があ る。

AR から聴力を推定する方法がいくつか考案されて (るが5) ${ }^{6)}$, 今回の被検児の中に全周波数で AR が得ら れない例のあったことは，AR 域値から聴力を判定す ることの限界を示している。しかし, ABRが無反応で $\mathrm{AR}$ が得られる例もある。当センターでは, $\mathrm{ABR}, \mathrm{AR}$ ともに実施し, $\mathrm{ABR}$ が無反応であった 29 例中 3 例に AR が認められている。その中の 1 例のオージオグラ ムを図 5 に示す。この例は ABR は無反応であったが, $500 \mathrm{~Hz}$ のみ $\mathrm{AR}$ が検出され聴力型が予測できた。乳幼 児の聴力はいくつかの検査を併用して判定することが 大切であり, AR も有用な検査項目のひとつである。

さて, AR 測定は㭘出耳の外耳道圧を tympanogram のピークに一致させて行うのが原則である。こ
の状態が鼓膜のコンプライアンスが最も高く, AR が 良く検出される。外耳道圧をピークに一致させない測 定による $\mathrm{AR}$ 域值の変化については, いくつかの報告 がある。Martin と (oombes ${ }^{7)}$ は, ピークより \pm 240 $\mathrm{mmH}_{2} \mathrm{O}$ の範囲で外耳道圧を加減し測定したが, $\mathrm{AR}$ 域値の上昇は $5.1 \mathrm{~dB}$ 以下にすぎなかったと報告して いる。Ruth ら ${ }^{8)}$ は, ピークょり $\pm 120 \mathrm{mmH}_{2} \mathrm{O}$ の範囲 で測定し, $\mathrm{AR}$ 域値の上昇は $4 \sim 8 \mathrm{~dB}$ であったとしてい る。これらの報告は, 対象が成人であり検出耳の tympanogram がA型であることが今回の検討と異な る。

今回の結果では AR 域値の上昇值を求める以前に, 半数以上の例 $(54 \%) て ゙ \mathrm{AR}$ を検出し得なくなってし まった。この理由として，成人に較べ乳幼児の $\mathrm{AR}$ 域 值が高いため, 測定可能音圧以上へと AR 域値が上昇 しやすいことが考えられる。しかし，いずれにせよ $\mathrm{AR}$ 測定は検出耳の外耳道圧を tympanogram のピークに 一致させて行う必要があることが明らかとなった。

tympanogram が+ A型であってもあくびにより A 型になることがあるし, 睡眠直後は $\mathrm{A}$ 型の耳が時間経 過により+A型となるのである1)。このため, 睡眠時に は tympanometry 後 AR 測定までに時間間隔を置く と, 外耳道圧をピークに一致させたつもりでも AR 測 定時にはピークが移動している可能性があり, ピーク が移動していれば，AR 測定結果は本来得られるべき 結果と著しく異なる。睡眠時には tympanometry 後, 直ちに $\mathrm{AR}$ 測定を実施する必要があり, 測定中も被検 児の状態 (あくびや体動の有無)を良く観察し，AR 測 定後に再度 tympanoretry を実施して, 初めのピーク の位置と変化ないことを確かめるのが望ましい。

\section{まと め}

睡眠下の乳幼児において, 中耳腔陽圧を示す tympanogram+ A 型の AR 域值を A 型の AR 域值と 比較した。さらに, + A型において $\mathrm{AR}$ 測定時の外耳 道圧の影響を検討した。

1. + A 型， A型間では AR 域值に明らかな差は認 められなかった。

2. 十 A 型において AR 測定時の外耳道圧を tympanogram のピークに一致させることが大切であ り，ピークに一致させないと測定結果に著しい差を招 くことがわかった。

3. ABR 無反応であっても AR を検出し得る場合 があり, AR 測定は乳幼児聴力検査のひとつとして有 
用である。

本論文の要旨は第30回日本オージオロジー学会にお いてロ演した。

The Acoustic Reflex on Positive Pressure Tympanogrom

Shinichi Okada (Ibaraki Medical Center)

Yuji Ase (University of Tsukuba Institute of Clinical Medicine)

Takashi Arai (Kasumigaura National Hospital)

Following ABR measurement, tympanogram was recorded and analysed in infants and children during sleep induced by sedatives. In this study, the middle ear cavity pressure in most of the subjects was increased in course of sleep, and we called this type as type $+\mathrm{A}$ tympanogram (positive pressure tympanogram).

The acoustic reflex threshold on type $+\mathrm{A}$ tympanogram was compared with that on type A.

The results were as follows.

There was no significant difference in threshold between both acoustic reflex of normal hearing subjects.

When ear canal pressure was not matched to the point of maximal compliance on tympanogram, acoustic reflex thereshold was elevated or absent.

Therfore, on measurement of acoustic reflex threshold, we emphasized that ear canal pressure must be matched to the point of maximal compliance of tympanogram.

\section{参考文献}

1）阿瀬雄治, 新井 峻, 飯田律子, 岡田慎一：睡眠 下乳幼児の中耳腔陽圧。Audiology Japan, 28；772 $-777,1985$

2）猪 忠彦，神崎 仁，小野 博，古賀慶次郎：乳 幼児のインピーダンスオージオメトリー一他覚的 聴力検査法としての臨床評価一。Audiology Japan, $20 ; 41-49,1977$

3) Jerger, S. Jerger, J. Mauldin, L. Segal, P. : Studies in impedance audiometry. II. Children less than 6years old. Arch. Otolaryngol., $99 ; 1-9$, 1974

4) Jerger, J. Jerger, S. Mauldin, L. : Studies in impedance audiometry. I. Normal and sensorineural ears. Arch. Otolaryngol., 96 ; 513-523, 1972

5) Jerger, J. Burney, P. Mauldin, L. Crump, B. : Predicting hearing loss from the acoustic reflex. J. Speech Hearing Disorders, 39 ; 11-12, 1974

6) Niemeyer, W. Sesterhenn, G. : Calculating the hearing threshold from the stapedius reflex threshold for different sound stimuli. Audiology, 13 ; 421-427, 1974

7) Martin, F. N. Coombes, S. : Effects of external ear canal pressure on the middle ear muscle reflex threshold. J. Speech Hear. Res., 17 ; 526-530, 1974

8) Ruth, R. A. Tucci, D. L. Nilo, E. R. : Effects of ear canal pressure on threshold and growth of the acoustic reflex. Ear Hear., 3 ; 39-41, 1982

（受付 60.2.18） 